\title{
ELECTRON PREINJECTOR FOR SIBERIA-2 SR SOURCE
}

\author{
O.A. Nezhevenko, G.N. Ostreiko, B.Z. Persov, \\ S.I. Ruvinsky, G.V. Serdobintsev, E.N. Shaimerdenov, \\ M.A. Tiunov, V.P. Yakovlev, I.A. Zapryagaev \\ Institute of Nuclear Physics, 630060 Novosibirsk, USSR
}

\section{$\underline{\text { Abstract }}$}

The $100 \mathrm{MeV}$ linear accelerator operating in stored energy mode is described. It is designed to inject the electron beam (with 15 ns pulse duration and $200 \mathrm{~mA}$ current within $1 \%$ energy spread) into the booster ring.

lhe linac design is based on the $2.8 \mathrm{GHz} \mathrm{DAW}$ structure with three radial stems. The developed construction is easy for fabrication and tuning and provides a good shunt impedance of $92 \mathrm{MOhm} / \mathrm{m}$ and the working frequency domain being free of high order modes. The structure consists of a single $6 \mathrm{~m}$ long section.

The accelerator has a simple injection system without a special buncher. The nonbunched $40 \mathrm{keV}$ beam formed by a diode gun is injected directly into the first DAW cavity

The focusing system is simple too. It is provided both by the matching lens in front of the structure and by an RF field and has no focusing elements in the acceleration channel.

The first results of the accelerator performance are presented.

\section{INTRODUCTION}

The complex «Siberia- $2 \%$, which will be built in Moscow [1] will serve to use as a SR source. It will

fronts on the beam dynamics. The beam parameters required on the injector output are given in Tabl. 1.

Beam energy

Beam current in a pulse

Pulse duration

Transverse emiltance

Repetition rate
Energy spread

$$
\begin{gathered}
\text { Table } 1 \\
80-100 \mathrm{MeV} \\
1 \% \\
200 \mathrm{~mA} \\
15 \mathrm{~ns} \\
0.1 \mathrm{mad} . \mathrm{cm} \\
1 \mathrm{pps}
\end{gathered}
$$

The modification of the DAW structure [2] with radial stems [3] was selected as an accelerating structure of the preinjector. Each washer is suppoited by three radial stems, which have the length close to $\lambda / 4$. The use of DAW structure at the stored energy mode enables one to solve the following problems:

- because of high shunt impedance one can reach maximum energy of electrons [4];

because of a large energy stored one can accelerate the beam with maximum current,

- because of high group velocity there is a possibility to perform an accelerating structure in the form of a single resonance section with a single power input and thus to avoid phasing of separate sections and also to simplify the reguirements to accuracy of manufacturing and tuning.

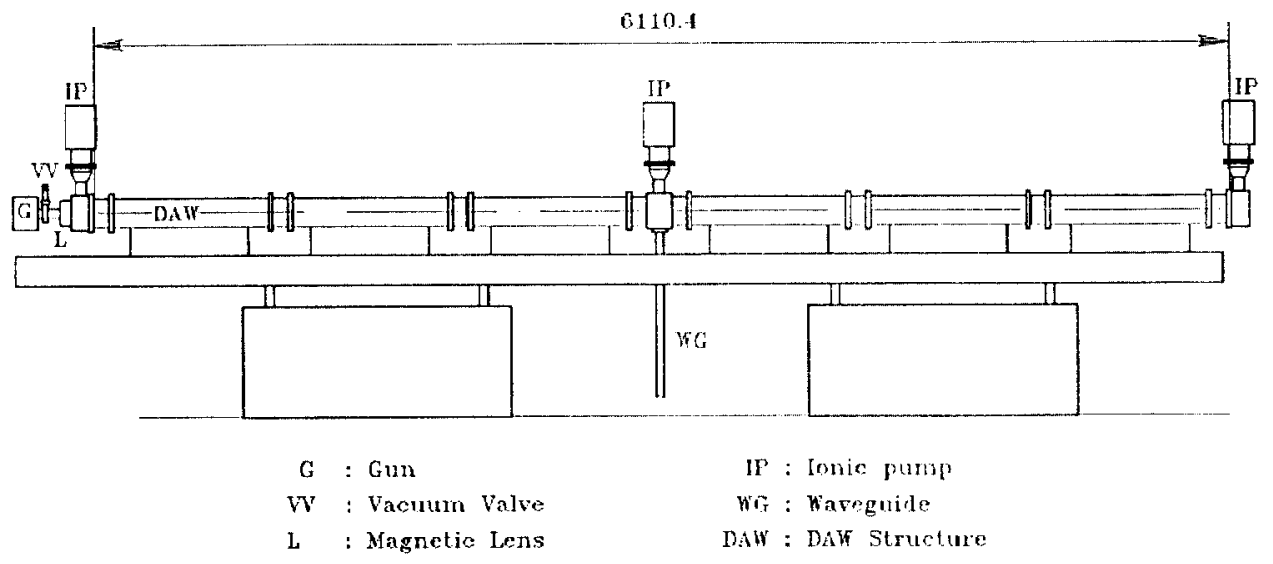

Fig. 1. The preinjector layout.

consist of a storage ring with $2.5 \mathrm{GeV}$ maximum energy as the main part and a combination of a 100 $\mathrm{MeV}$ electron linac and a $450 \mathrm{MeV}$ booster ring «Siberia-1» as an injection part.

This report is dedicated to description of the 100 MeV linac-preinjector shown in Fig. 1.

\section{OPERATING MODE}

The booster ring «Siberia-l» will work at a single bunch rnode with revolution time of $30 \mathrm{~ns}$. Therefore the injector current pulse duration should not exceed 15 $n s$ in order to avoid the influence of the injector

\section{BEAM DYNAMICS}

The accelerator has a single injection system without a special buncher (Fig. 2). The same injection system had been developed for the linac-positrons source of the complex VEPP-4 [5].

The nonbunched $40 \mathrm{keV}$ beam formed by a diode gun is injected directly into the first resonator of the structure. The diode gun is shown in Fig. 3. The $\mathrm{LaB}_{6}$ spherical cathode has diameter of $16.4 \mathrm{~mm}$. The gun forms the parallel electron beam with the current of $4 \mathrm{~A}$ and with the diameter of $8 \mathrm{~mm}$ directly after the anode hole. 


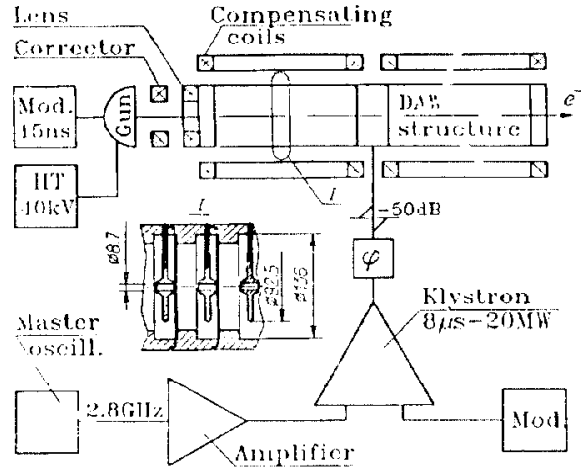

Fig. 2. The beam orming systen and RF system.

A beam bunching is realized in the first resonator, which consists of the regular halfsell with the plate front wall. The calculated beam spectrum at the accele-

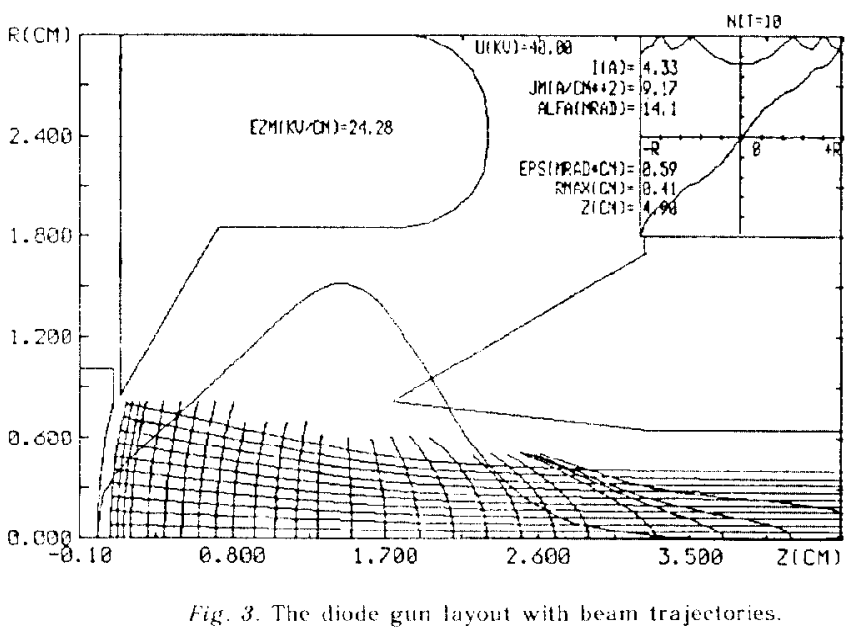

rator output is shown in Fig. 4. From this figure one can see, that the beam spectrum density change at the

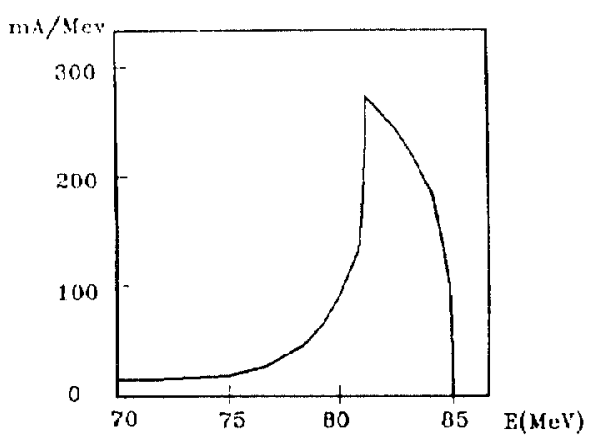

Fig. 4. The beam energy spectrum in the preinjector output.

electron energy about $80 \mathrm{Mev}$ is little, within of $5 \%$ relative energy range. Because of this, one can provide the stable injection current under an unstable RF voltage.

The focusing system is simple too (Fig. 2). It is urovided both by the matching lens in front of the structure and by an RF field of the first resonator. Also for a decrease in the focusing RF field influence under beam flying one must set a net in the first resonator input. It is provided essentially to decrease the beam emittance in the first resonator output and to do without additional focusing elements in the accelerating channel. Also in the beam travelling system there are a corrector for parallel shift and coils for compensating the Earth magnetic field.

The calculations by means of computer code based on the macro particle model show, that the beam emittance in the accelerator output will not exceed of $5 \cdot 10^{-2} \mathrm{mrad} \cdot \mathrm{cm}$, and the beam radius will not exceed more of $60 \%$ of the aperture.

\section{RF SYSTEM}

The preinjector RF system is shown in Fig. 2. It consists of the generator connected to accelerating structure by means of $90 \times 45 \mathrm{~mm}^{2}$ vacuumable rectangular waveguide. Power input is in the middle of the structure. Since we concentrated on use of the only one

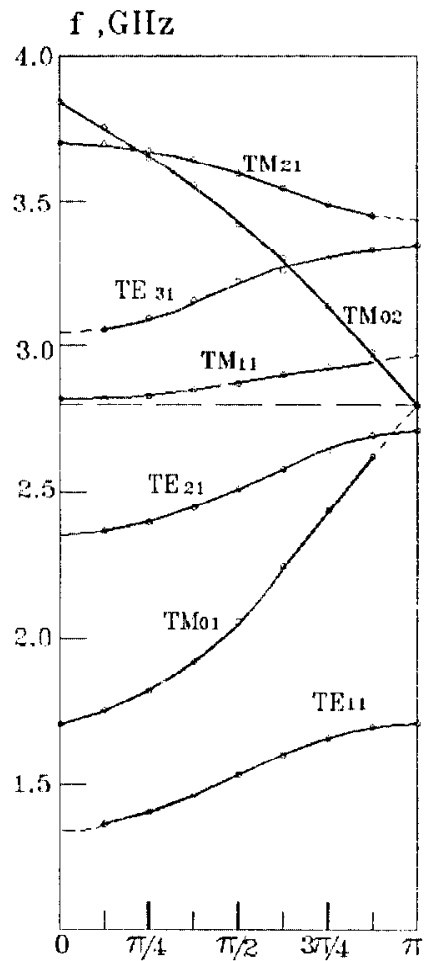

Fig. 5. The DAW structure modes spectrum.
$S$-band generator of $20 \mathrm{MW}$ power [6] therefore the full length of the DAW structure was selected of $6 \mathrm{~m}$.

As a result of numerical and experimental research [7] the optimal geometry of DAW structure provided a good shunt impedance of $92 \mathrm{MOhm} / \mathrm{m}$ and absence of high order modes within $\pm 20 \mathrm{MHz}$ concerning working mode like - TM $\mathrm{T}_{02 \pi}$ was selected. The dispersion curves of the structure are given in Fig. 5 .

The thermal test of the $1 \mathrm{~m}$ long section of structure showed that the temperature gradient of the frequency change is of $50 \mathrm{kHz} / \mathrm{deg} \mathrm{C}^{\circ}$

The $0.6 \mathrm{~m}$ long section of structure has been iested at high power [8]. The stable voltage pulse was received in 8 hours of

training by means of multipacting and breaks in the leading edge. The field level received on surface of structure corresponds to accelerating gradient of $15 \mathrm{MeV} / \mathrm{m}$.

The DAW structure parameters are given in Tabl. 2.

$$
\begin{aligned}
& \text { Frequency, } \\
& \text { Eff. charact. res., } \\
& \text { Quality factor, } \\
& \text { Overvoltage coef., } \\
& \text { Rel. group velocity, } \\
& \text { Length, }
\end{aligned}
$$

Ta ble 2

\begin{tabular}{c|c}
$f_{\exp }$ & $2795.7 \mathrm{MHz}$ \\
$\rho$ & $3.4 \mathrm{kOhm} / \mathrm{m}$ \\
$Q_{\exp }$ & 27000 \\
$k_{0}$ & 4.0 \\
$\beta_{g}$ & 0.4 \\
$L$ & $6.1 \mathrm{~m}$
\end{tabular}

\section{CURRENT STATUS}

At that time all preinjector systems had been mounted into the complex $\ll$ Siberia-2 $*$ accelerating hall. The measurements of the DAW structure at low power level had been made. The shunt impedance experimental value is of $92 \mathrm{MOhm} / \mathrm{m}$. The accelerating structure had been matched with the waveguide. In the accelerating structure and waveguide had been received vacuum. 
The electron gun feed system and klystron master oscillator had been tested. At present, the preinjector is ready for operation.

\section{CONCLUSION}

From the description given above one can single out the following points of interest:

- the use of the DAW structure allowed to design the compact preinjector more efficient compared to the traditional linacs based on the disk-loaded waveguides. For example, the $100 \mathrm{MeV}$ preinjector of the SR source described in report [9] requires the generator with close to twice as much power at the same full length and the more complicated prebunching system.

\section{REFERENCES}

[1] V.V. Anashin et al. Proc of the EPAC, Rome, June 7-11, 1988, p.57.

[2] V.G. Andreev. ZhTPh, 1971, vol.41, pp.788-796.

[3] S.O. Shriber. IEEE Trans, on Nucl. Sci., NS-30, N 4, 1983, pp.3542-3544.

[4] M.M. Karliner et al. Preprint INP 86-146, Novosibirsk, 1986, p.38.

[5] G.I. Budker et al. Proc of the 5-te All-1/nion Workshop on Acc., Dubna, 1977, vol.1, p.280.

[6] V.I. Beloglazov et al. Voprosy at. nauki i tehn., TPhE. 1985 vol.3(24), S.1-87, pp.8 9 .

[7] M.M. Karliner et al. Proc, of the EPAC, Rome, June $7-11$, 1988, vol.1, pp. $602-604$

[8] V.M. Borovikov et al. Voprosy at. nauki i tehr..JaPhI, 1989, vol.5(5), S.1-104, pp. $13-16$

[9] C. Bourat et al. Proc. of the IEEE Part. Accel. Coni., Chicago, IL, March 20-23, 1989, vol.2, pp.935-937. 